\title{
Application of Polyvinyl Acetate (PVAc) in Dye Sensitized Solar Cells (DSSC) as Electrolyte in The Presence of Acetonitrile as Highly Soluble Organic Solvent and KI as Inorganic Redox Salt
}

\author{
Shafi ur Rehman ${ }^{1}$, Hizb Ullah Khan ${ }^{2}$, Muhammad Khitab Ahmed $^{3}$, Rizwan Kamal ${ }^{4}$ \\ ${ }^{1,4}$ US Pakistan Center For Advanced Studies in Energy, University of Engineering and Technology, Peshawar \\ ${ }^{2}$ National Center of Excellence in Physical Chemistry University of Peshawar \\ ${ }^{3}$ National University of Engineering \& Technology (NUST), Islamabad, Pakistan \\ engr.shafi2962@gmail.com ${ }^{*}$, hizbullah382@gmail.com², khitab.770@gmail.com³, rkrizwan891@gmail.com ${ }^{4}$ \\ Received: 22 June, Revised: 02 July, Accepted: 09 July
}

\begin{abstract}
The dye sensitized solar cells technology is one of the highly efficient, low cost and easily fabricated renewable energy technology. The highly soluble PVAc was prepared by solution polymerization. The PVAc was employed as an electrolyte in third generation, Dye sensitized solar cell (DSSC). The PVAc was characterized using SEM, XRD and conductivity measuring techniques. The prepared electrolyte behaved as gel electrolyte. SEM images shows the excellent dispersion PVAc in liquid electrolyte. The conversion efficiency achieved using gel electrolyte was $4.18 \%$, which was comparable to liquid electrolyte with a value of $4.57 \%$. This new technique reduces the degradation of DSCs rising from volatilization and leakage of the liquid electrolyte and endorses the commercialization process of DSSC.
\end{abstract}

Keywords - Polyvinyl acetate, Acetonitrile, Gel electrolyte, Dye sensitized solar cell.

\section{INTRODUCTION}

Solar cells are the renewable energy resources that pick up their energy from sun and supply this endless energy for human beings. It is one of the most hopeful energy resources due to its profusion, purity, safety and higher economic values that causes energy creation in distant rural areas [1]. The Solar energy can be used for three purposes: Photoelectric energy i.e. Solar PV, solar thermal energy and passive solar energy [2]. Technology of producing electricity directly from the solar energy was discovered by Alexander Edmond Becquerel, who was a French physicist at 1839 and that was the start of solar energy [3]. A solar cell is an electric device that directly convert incident light into electricity by photovoltaic effect [4].

The solar cell technology is grouped into three different generations, as shown in Fig.1. Illustration of solar cell technology, it is grouped into first, second, and third generations and These generations are additionally arranged into various kinds [5].
In 1991 the seminal work was initiated on DSSCs by O'Regan and Grätzel [6]. The DSSC is an emerging technology which is one of the third generation PV technology.

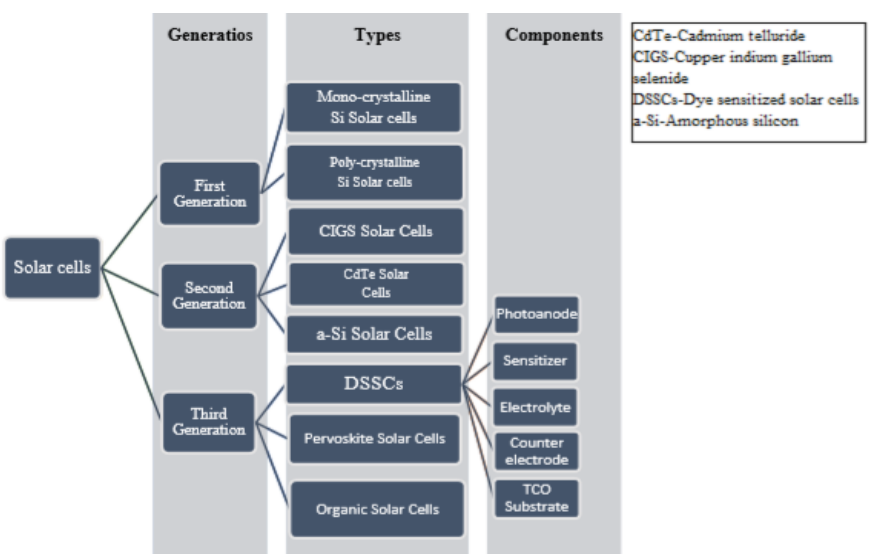

Figure 1. Illustration of solar cell technology, it is grouped into first, second, and third generations and These generations are additionally arranged into various kinds [5].

An extensive research has been made in this technology on its applications during the last two decades because of its cheaper and easier fabrication process [7]. This technology mimics the natural photosynthesis in the way of light absorption [8]. DSSCs work better than other PV devices in dark condition that is in cloudy climate or in sunset and in diffused light radiations which makes it outstanding choice for indoor applications like sunroof and windows [9]. So far, the efficiency achieved by DSSC is from $\sim 7 \%$ to $\sim 14 \%$ [10]. A DSSC basically comprises a semiconductor (e.g. $\mathrm{ZnO}, \mathrm{SnO} 2$ and $\mathrm{TiO} 2$ etc.) of few microns thick film as working electrode that is coated on transparent conducting substrate, a dye i.e. Organic dye or inorganic metal complex dye, a counter electrode (e.g. carbon materials and Pt etc.) also coated on conductive glass substrate and an electrolyte (i.e. $\mathrm{Co} 2+/ \mathrm{Co} 3+$ and I3-/I- etc. as a redox couples) inserted between counter electrode and dye, as shown in Fig.2 [11]. The light is absorbed 


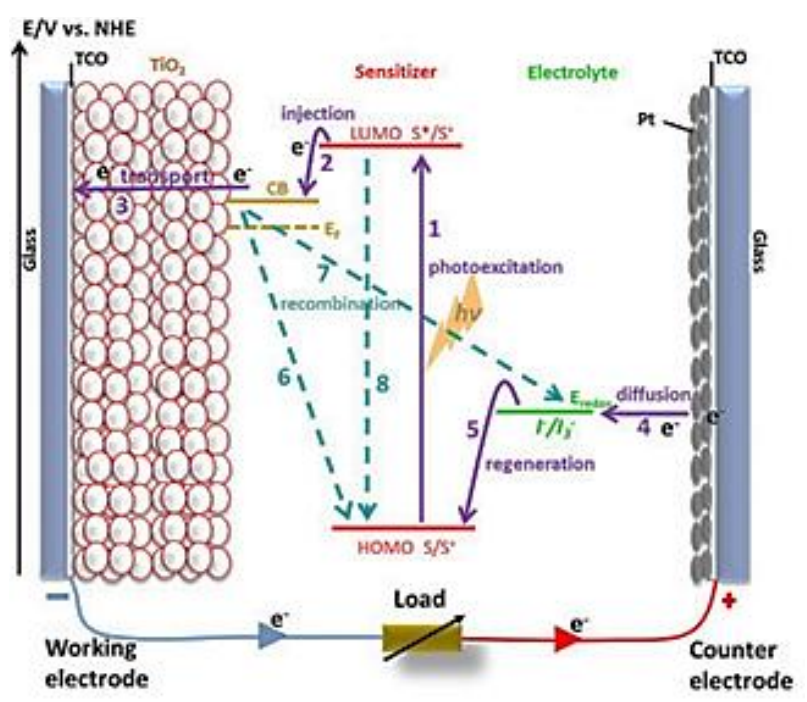

Figure 2. Working principle of $\mathrm{TiO}_{2}$ based

by the dye molecules and electrons are injected into the conduction band of semiconductor. The electrolyte in contact with dye, provide electrons to the oxidized dye and restores it to its initial state. Then the oxidized electrolyte moves toward counter electrode and reduced to its neutral state [13].

The organic solvents have the volatility problem of its solvent caused by thermal stress and as a result cell deterioration is caused over long use. Consequently, ionic liquid solvents have been the promising electrolyte because of its good thermal and chemical stability, tuneable viscosity, high ionic conductivity and low volatility. Researchers are in interest to discover new liquid electrolyte, to increase the efficiency of DSSCs, such as 1,3-dialkylimidazolium etc. $[14,15]$. Low-viscosity ionic liquid is mixed with imidazolium iodide, to higher the efficiency [15].

Polymers has a unique network structure in gel electrolyte and shows, long term stability, higher electrical conductivity and good interfacial contact as compare to liquid electrolyte [16]. Polyvinyl acetate was discovered by Germany scientist Fritz Klatte in 1912. The manufactured polymer has the formula $(\mathrm{C} 4 \mathrm{H} 6 \mathrm{O} 2) n$ and the general formula with the polyvinyl esters family is - [RCOOCHCH2] -. It is a kind of thermoplastic materials and its IUPAC name is poly (1acetyloxiethene). Polyvinyl acetate is profoundly soluble polymer in organic solvents $[17,18]$.

This study, therefore demonstrate the application of polymer in DSSC's electrolyte in the presence of acetonitrile as solvent and KI (potassium iodide) as redox ion. The prepared Polymer was characterized through FTIR, XRD and the IV characteristics was done by solar simulator.

\section{EXPERIMENTAL}

\section{A. Materials:}

Vinyl acetate, sodium dodecyl sulphate, acetone and ethanol were purchased fromuni-chem Lab Ltd (india) whereas KI, iodine and acetonitrile from Schalab SL (Spain). The FTO glasses and N3 dye was obtained from Solaronics (Switzerland). All the chemicals purchased were in pure form.

\section{B. Synthesis of PVAc}

The Polyvinyl acetate was synthesized with the help of free radicle solution polymerization technique. Simply, $30 \mathrm{~mL}$ of monomer vinyl acetate was taken in flask and in a certain amount of water and $5 \mathrm{~mL}$ of methanol and $0.1 \mathrm{G}$ of ammonium persulfate ((NH4)2S2O8) as an initiator were added. The reaction was refluxed at $70{ }^{\circ} \mathrm{C}$ for 2 hours. Once the mixture turned gelatinous $40 \mathrm{~mL}$ of methanol was mixed to the system and then stopped heating. The prepared polymer was dried in vacuum chamber for 24 hours at $40{ }^{\circ} \mathrm{C}$. Then it is characterized for further applications.

\section{Electrolyte preparation:}

The prepared liquid electrolyte consisted of $0.4 \mathrm{M} 1$ methyl-3-propyl imidazoulium iodide, $0.2 \mathrm{M} \mathrm{Kl}, 0.3 \mathrm{M}$ pyridine in acetonitrile as solvent. A $0.4 \mathrm{~g}$ of the PVAc was mixed with $1.5 \mathrm{~g}$ of liquid electrolyte and then mixer was stirred till complete dissolution of the polymer and then the electrolyte converted into quasi solid electrolyte and then employed both the electrolytes in DSSC separately. The prepared gel and Liquid electrolytes and DSSC module are shown in Fig.3.
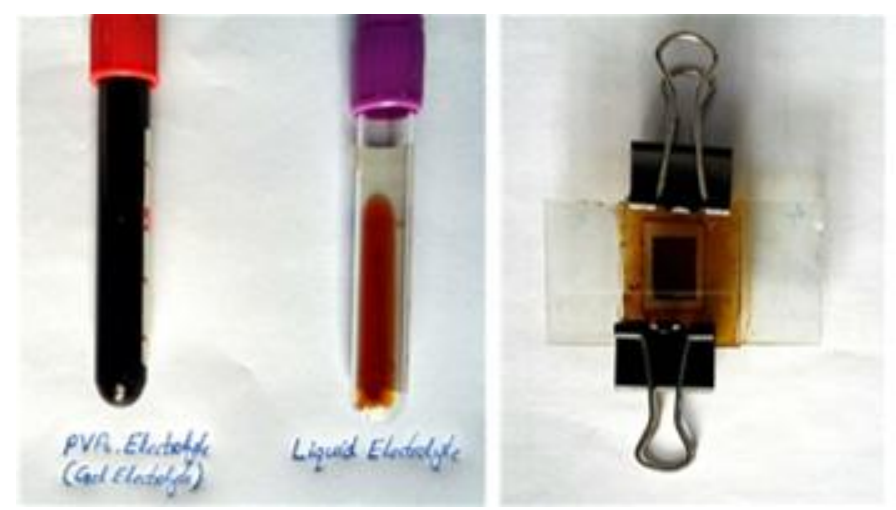

Figure 3. Liquid and Gel Electrolyte prepared in Lab

\section{RESULTS AND DISCUSSION}

\section{A. SEM Micrographs:}

The SEM micrograph of PVAc is shown in fig 4. The fig 4. (a) shows that PVAc has uniform, non-porous and amorphous structure while fig 4. (b) shows the scanning electron micrograph of the gel electrolyte on the $\mathrm{TiO} 2$ working electrode. 


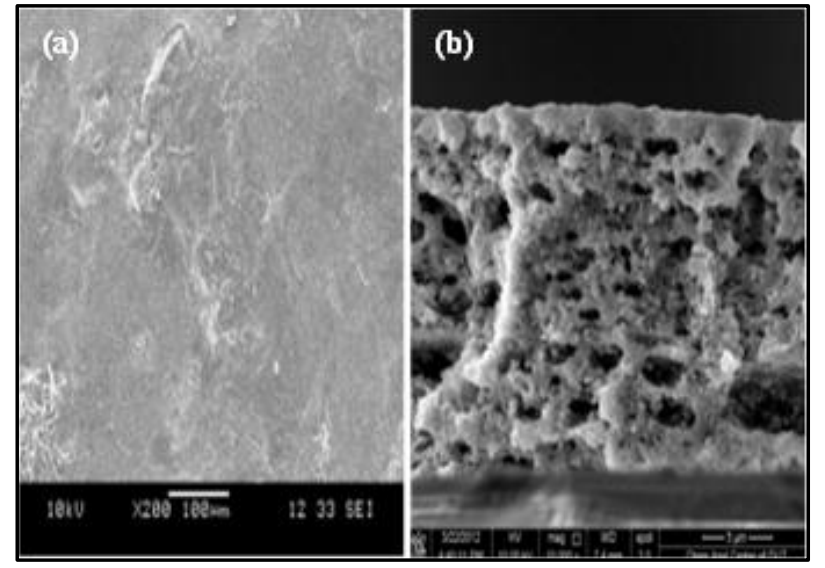

Figure 4. SEM image of (a) PVAc pure and (b) PVAc as gel electrolyte.

As shown in the figure, the $\mathrm{TiO} 2$ surfaces are completely covered by the gel electrolyte. The big holes show the spongy network of PVAc through which the liquid electrolyte can pass through it and retains the volatility of the organic solvent by making bond with acetonitrile as a result stability of DSSC is improved.

\section{B. XRD Analysis:}

As shown in Fig 5. native PVAc is amorphous as expected. The peaks at 15o, 22o represent PVAc. As the figure shows the almost zero peaks which shows that it has non-crystalline structure [20].

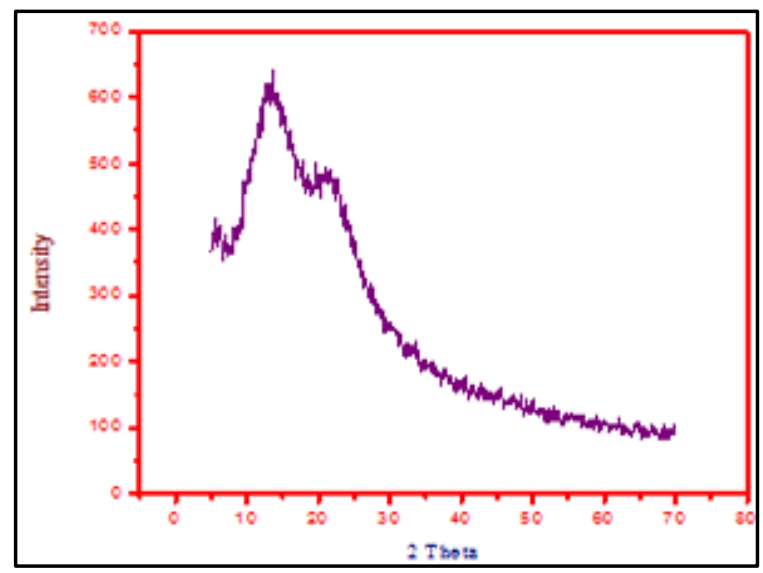

Figure 5. XRD Diffractogram of PVAc

\section{Electrical Conductivity:}

The fig 6 showed the conductivity of $2.3 \times 10-3 \mathrm{~S} / \mathrm{cm}$ at high frequency of PVAc. The lower conductivity of the polymer is because of low level protonation of PVAc chain. The increase of the polymer conductivity with frequency is the radiation which cause splitting of the polymer chain. The conductivity is based upon electronic jumping which cause high energy free electrons, ions [19-22]. The fig 7 shows the conductivity of the gel electrolyte. This increase of the electrolyte conductivity is due to the free iodide ions present in the liquid electrolyte.

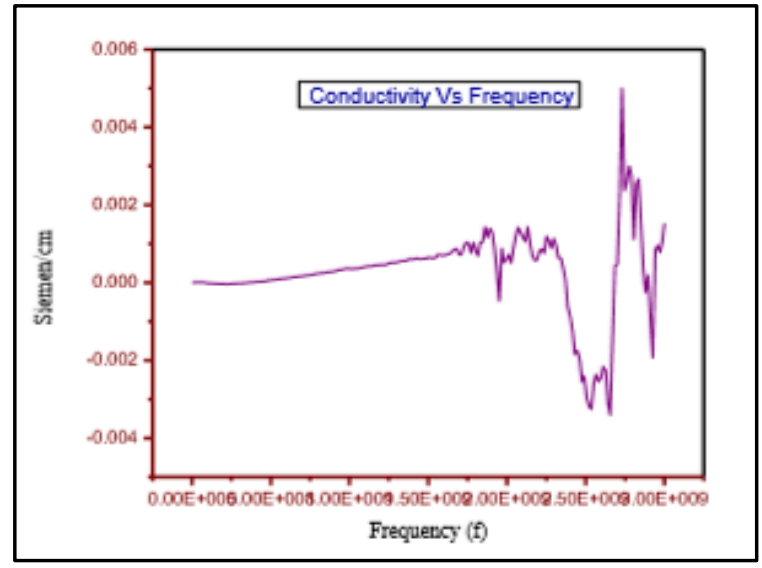

Figure 6. Conductivity of PVAc

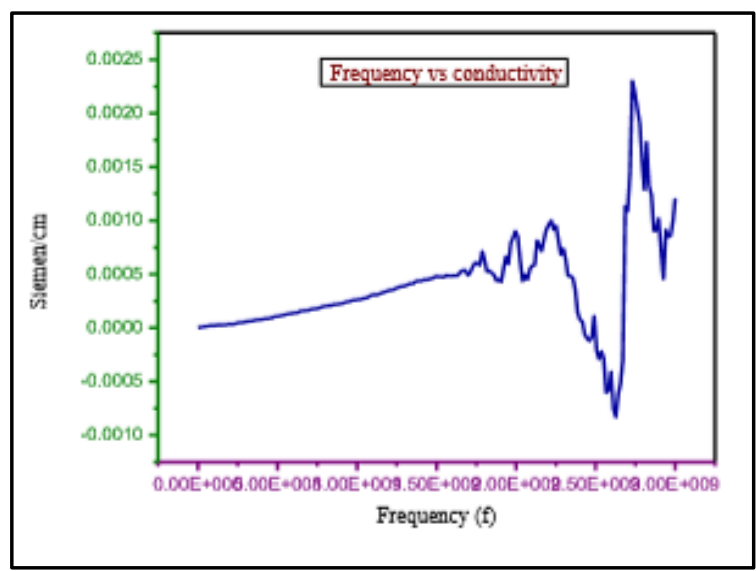

Figure 7. Conductivity of Gel Electrolyte

\section{Performance Parameters:}

The photovoltaic performance was done under illumination (AM 1.5G, $100 \mathrm{~W} \mathrm{cm-2)} \mathrm{on} \mathrm{DSSC} \mathrm{employing} \mathrm{gel} \mathrm{electrolyte}$ as shown in fig 7. The Voc, Jsc and FF of DSSC based on liquid and gel electrolyte are $0.712 \mathrm{~V}, 12.78 \mathrm{mAcm}-2$ and 57 $\%$, respectively, yielding conversion efficiency of $4.18 \%$. The values (Voc, Jsc, FF, and $\eta$ ) for the liquid electrolyte are 0.686 $\mathrm{V}, 13.88 \mathrm{~mA} \mathrm{~cm}-2,59 \%$, and $4.57 \%$, respectively. By comparing the data of the two electrolytes show that the increase of the Voc of liquid electrolyte is compensated by the slight decrease of FF of the gel electrolyte.

\section{CONCLUSION}

In summary, the highly soluble PVAc was prepared by solution polymerization. The PVAc was employed as an electrolyte in DSSC. The PVAc was characterized using SEM, $\mathrm{XRD}$ and conductivity measuring techniques. The prepared electrolyte behaved as gel electrolyte. SEM images shows the excellent dispersion PVAc in liquid electrolyte. The conversion efficiency achieved using gel electrolyte was $4.18 \%$, which was comparable to liquid electrolyte with a value of $4.57 \%$. the gel electrolyte has the advantage of high efficiency, cheap, easy fabrication, environmentally friendly and stable. As a result, the stability and efficiency of DSSC can be improved by 
improving the conductivity of the gel electrolyte in case of polymer nanocomposite.

\section{ACKNOWLEDGMENT}

We would like to acknowledge Assistant Professor Dr. Muhammad Noman for his valuable knowledge and experience which helped us in achieving this milestone. We are also thankful to our fellow students, faculty and all the staff members of United States Pakistan Center for Advanced Studies in Energy (US.PCAS-E) at UET Peshawar for their support in this work. We are also thankful to USAID for providing us financial support in our MS studies.

\section{REFERENCES}

[1] Su'ait, M. S., Rahman, M. Y. A., \& Ahmad, A. (2015). Review on polymer electrolyte in dye-sensitized solar cells (DSSCs). Solar Energy, $115,452-470$.

[2] Mussard, M. (2017). Solar energy under cold climatic conditions: A review. Renewable and Sustainable Energy Reviews, 74, 733-745.

[3] Kibria, M. T., Ahammed, A., Sony, S. M., Hossain, F., \& Islam, S. U. (2014). A Review: Comparative studies on different generation solar cells technology. In Proc. of 5th International Conference on Environmental Aspects of Bangladesh.

[4] Bagher, A. M., Vahid, M. M. A., \& Mohsen, M. (2015). Types of solar cells and application. American Journal of Optics and Photonics, 3(5), 94-113.

[5] Kumar, S., Nehra, M., Deep, A., Kedia, D., Dilbaghi, N., \& Kim, K. H. (2017). Quantum-sized nanomaterials for solar cell applications. Renewable and Sustainable Energy Reviews, 73, 821-839.

[6] Gong, J., Sumathy, K., Qiao, Q., \& Zhou, Z. (2017). Review on dyesensitized solar cells (DSSCs): Advanced techniques and research trends. Renewable and Sustainable Energy Reviews, 68, 234-246.

[7] Yun, S., Freitas, J. N., Nogueira, A. F., Wang, Y., Ahmad, S., \& Wang, Z. S. (2016). Dye-sensitized solar cells employing polymers. Progress in Polymer Science, 59, 1-40.

[8] Bagher, A. M., Vahid, M. M. A., \& Mohsen, M. (2015). Types of solar cells and application. American Journal of Optics and Photonics, 3(5), 94-113.

[9] Al-Alwani, M. A., Mohamad, A. B., Ludin, N. A., Kadhum, A. A. H., \& Sopian, K. (2016). Dye-sensitised solar cells: Development, structure, operation principles, electron kinetics, characterisation, synthesis materials and natural photosensitisers. Renewable and Sustainable Energy Reviews, 65, 183-213.

[10] Lee, C. P., Li, C. T., \& Ho, K. C. (2017). Use of organic materials in dye-sensitized solar cells. Materials Today.

[11] Ye, M., Wen, X., Wang, M., Iocozzia, J., Zhang, N., Lin, C., \& Lin, Z. (2015). Recent advances in dye-sensitized solar cells: from photoanodes, sensitizers and electrolytes to counter electrodes. Materials Today, 18(3), 155-162.

[12] Kumara, N. T. R. N., Lim, A., Lim, C. M., Petra, M. I., \& Ekanayake, P. (2017). Recent progress and utilization of natural pigments in dye sensitized solar cells: A review. Renewable and Sustainable Energy Reviews, 78, 301-317

[13] Mehmood, U., Al-Ahmed, A., Al-Sulaiman, F. A., Malik, M. I., Shehzad, F., \& Khan, A. U. H. (2017). Effect of temperature on the photovoltaic performance and stability of solid-state dye-sensitized solar cells: A review. Renewable and Sustainable Energy Reviews, 79, 946959.

[14] Lee, C. P., Li, C. T., \& Ho, K. C. (2017). Use of organic materials in dye-sensitized solar cells. Materials Today, 20(5), 267-283.
[15] Yusof, S. M. M., \& Yahya, W. Z. N. (2016). Binary ionic liquid electrolyte for dye-sensitized solar cells. Procedia engineering, 148, 100105.

[16] Mohamad, A. A. (2016). Absorbency and conductivity of quasi-solidstate polymer electrolytes for dye-sensitized solar cells: A characterization review. Journal of Power Sources, 329, 57-71.

[17] Mittal, G., Dhand, V., Rhee, K. Y., Park, S. J., \& Lee, W. R. (2015). A review on carbon nanotubes and graphene as fillers in reinforced polymer nanocomposites. Journal of Industrial and Engineering Chemistry, 21, 11-25.

[18] https://en.wikipedia.org/wiki/Polyvinyl_acetate\#cite_note-1. 23 sept. 2018.

[19] Fares, S. (2011). Frequency dependence of the electrical conductivity and dielectric constants of polycarbonate (Makrofol-E) film under the effects of [gamma]-radiation. Natural Science, 3(12), 1034

[20] Yeum, J. H., Park, J. H., Choi, J. Y., Kim, J. W., Han, S. K., \& Oh, W. Polymer/Montmorillonite/Silver Nanocomposite Micro-and Nanoparticles Prepared by In-Situ Polymerization and Electrospraying Technique.

[21] Safenaz, M. R., \& Sheikha, M. (2012). Synthesis and electrical properties of polyaniline composite with silver nanoparticles. Advances in Materials Physics and Chemistry, 2012.

[22] Fares, S. (2011). Frequency dependence of the electrical conductivity and dielectric constants of polycarbonate (Makrofol-E) film under the effects of [gamma]-radiation. Natural Science, 3(12), 1034.

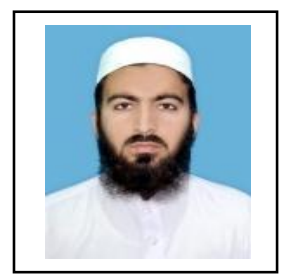

Shafi ur rehman has received B.Sc Mechanical Engineering degree from department of Mechanical Engineering University of Engineering and Technology Peshawar, Pakistan in 2014. He is currently pursuing M.Sc degree in Materials for energy storage and conversion from United States Pakistan Center for Advanced Studies in Energy (USPCAS-E) at University of Engineering and Technology Peshawar. He worked on Third generation solar cells that is Dye sensitized solar cells to improve its performance and stability. 